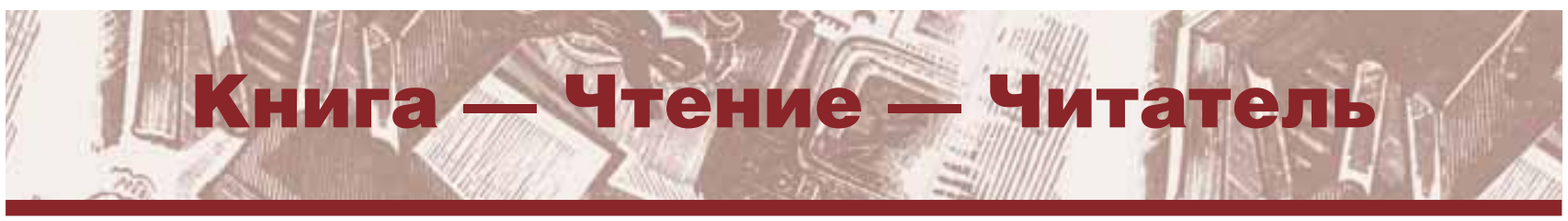

УДК 930.85(47)"18/20"

ББК $76.10(2) 6,35$

DOI 10.25281/0869-608X-2020-69-3-271-280

\title{
A.B. ПЕTРОВА
}

\section{Изучение рукописных альбомов в отечественной науке (XIX - начало XXI века)}

Реферат. Статья посвящена библиографии изучения русских альбомов (XIX - начала XXI века). Развитие отечественной историографии этой темы проходило неравномерно. В статье последовательно описаны три главных этапа в исследовании рукописного альбома: отклик современников и публичные обсуждения этого явления; начало публикаций альбомных текстов; введение альбомов в науку. Представлены основные направления академических исследований. Рассматриваются отечественные публикации о русских альбомах, начиная с первой четверти XIX в. по начало XXI века. Анализ литературы об альбомах проводился с точки зрения области интересов автора (изучение истории альбомов автографов, их типологии и функции), характера и объема исследуемых объектов, основных задач этих работ и их методологических принципов. Основной проблемой в историографии темы является разработка типологии рукописных альбомов. Выбор типологии как основного предмета анализа связан с тем, что в целом это явление русской культуры конца XVIII - первой четверти XX в. не подверглось систематическому рассмотрению. Для создания полноценной картины русской альбомной культуры необходимо, в первую очередь, выстроить типологическую систему. Результатом исследования стал полный обзор публикаций по русским рукописным альбомам, вышедшим с 1820 по 2016 год. Выделены основные типологические принципы альбомов, характерные для разных подходов, исследовательских школ и направлений. Отмечается, что многие вопросы до настоящего момента остались не рассмотренными. Вне изучения находится подход к альбому как источнику по истории индивидуального письма и социокультурного поведения, в то время как комплексный анализ русского альбома, письма и подписи в нем является одним из перспективных направлений исследования культуры повседневности XVIII-XX веков. Автор делает вывод об отсутствии в историографии универсальной типологии, которую предлагается представить в следующих работах.

Ключевые слова: искусствоведение, художественная культура, культура повседневности,

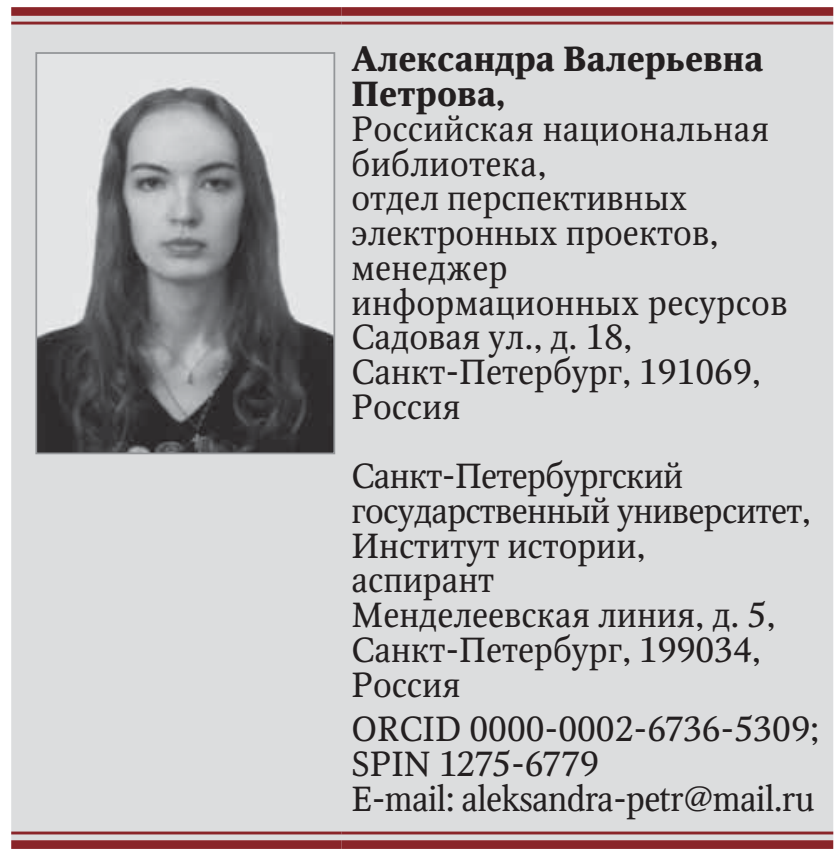


автографы, альбомная культура, визитные книги, коллекционирование, рукописные альбомы, Институт русской литературы (Пушкинский Дом) РАН, типология рукописных альбомов, индивидуальное письмо, библиография, историография.

Для цитирования: Петрова А.В. Изучение рукописных альбомов в отечественной науке (XIX начало XXI века) // Библиотековедение. 2020. T. 69, № 3. С. 271-280. DOI: 10.25281/0869-608X2020-69-3-271-280.

$\mathrm{P}$ укописные альбомы представляют собой важную составляющую культуры повседневности конца XVIII - первой четверти $\mathrm{XX}$ в. (до 1920-х гг.). Интерес к изучению этого явления возник в связи с распространением альбомов в русском дворянском обществе, когда из «домашней тетради» альбом превратился в обязательную принадлежность светской жизни.

Первые публичные обсуждения альбомной культуры обнаруживаются в русских журналах в 1820-1840-х годах. Авторы пытались оценить значение альбомов для общества, их влияние на литературную, музыкальную и театральную среду, появились как сторонники альбомов (П.Л. Яковлев [1]), так и их противники (Н. Виршеевский [2]). Помимо оригинальных работ публиковались переводы (в основном с французского языка), посвященные увлечению альбомной культурой в Европе XVIII-XIX веков. Некоторые современники не ограничивались бытовыми заметками об альбомах, а предпринимали попытки их первой классификации [3].

Второй этап в изучении рукописных альбомов начался в конце XIX в. и продолжался до конца 1920-х годов. Эпоха «домашних» и «салонных» альбомов уходила в прошлое, теперь они стали интересны как предметы старины. Альбом из факта повседневности превратился в историко-культурный источник. В отечественную науку рукописные альбомы были введены благодаря деятельности первых собирателей и коллекционеров, которые публиковали тексты в российских журналах: «Русский архив», «Русская старина», «Исторический вестник», «Русский библиофил» и др. Издание стихов, прозаических отрывков и других записей тесно связано с историей создания Пушкинского Дома и деятельностью Отделения русского языка и словесности Императорской академии наук.

Однако системное изучение русских рукописных альбомов начинается со второй половины XX века. В работах отечественных литературоведов были продолжены традиции изучения альбомов, заложенные в предыдущие десятилетия. В стенах Пушкинского Дома (Институт русской литературы (ИРЛИ) АН СССР) М.П. Алексеев [4] и В.Э. Вацуро [5] создают обобщающие работы об альбомах XIX века. В целом исследования литературоведов были по-прежнему сосредоточены вокруг альбомных текстов. Преимущество отдавалось рукописям, содержащим автографы А.С. Пушкина и его окружения. Другим центром исследования являлась московско-тартуская школа, для которой характерно изучение альбомного текста как знаковой системы [6].

«Современный» альбом ХХ в. стал объектом внимания фольклористов. А.Ю. Ханютин [7], М.В. Калашникова [8], А.В. Чеканова [9] предприняли попытку создать свою типологию и проследить эволюцию альбома: от «домашнего» альбома XIX в. до «анкеты» XXI века. Немало места в работах уделено разбору функций альбома. В новейшее время наметилась тенденция его рассмотрения как социокультурного источника по истории XIX в. [10].

Особняком в изучении русских альбомов стоит искусствоведческое направление, возникшее в 1980-е гг. и представленное в работах Т.Г. Цявловской [11], А.В. Корниловой [12], В.А. Черновой [13]. В рамках этого подхода объектом изучения является изобразительный материал (рисунки, наброски, акварели, аппликации). При этом основное внимание уделяется автографам известных художников и литераторов.

Кратко описав историю изучения русских рукописных альбомов, мы можем более подробно рассмотреть наиболее значимые исследования.

Началом изучения альбомов можно считать полемику между Н. Виршеевским ${ }^{1}$ и П.Л. Яковлевым, разгоревшуюся на страницах журнала «Благонамеренный»² в 1820 году. Н. Виршеевский опубликовал статью «О альбомах (Письмо к издателю от одного ученого из Колтовской)» [2], в которой назвал их явлением моды, перешедшей из центра (с Невского проспекта) на культурную периферию 
(в Колтовскую слободу): «...не одни покрои платья перешли к нам от жителей города. Мы одолжены им изобретением альбома...» [2, с. 23-24]. Автор является противником альбомной культуры, основной вред которой он видит в «светском распылении» литературных и творческих талантов русского общества. Н. Виршеевский проводит прямую связь между заполнением альбомов и оскудением репертуаров российских театров, ухудшением качества прозаических и поэтических произведений.

Ответом на такую критику стала статья публициста П.Л. Яковлева, принадлежавшего к литераторам пушкинского круга [1]. Он сам неоднократно оставлял записи в альбомах и выступал в защиту альбомной культуры. П.Л. Яковлев отмечал благотворное воздействие альбомов на «умение писать и говорить», и в целом на развитие литературного вкуса: «...со времени появления альбомов, у нас стали писать лучше, приятнее; выражаться приличнее, свободнее, ближе к общественному разговору...» [1, с. 375]. Здесь мы видим еще и отголоски спора о русском литературном языке $^{3}$. П.Л. Яковлев явно поддерживает сторону «карамзинистов», а альбом считает одним из инструментов проведения языковой реформы [15, c. 20-25].

В статье «Альбомы», опубликованной в 1828 г. в сборнике «Записки москвича» [3], П.Л. Яковлев пошел по пути исследования, в котором уже предложил типологию, предприняв первую попытку систематизации современных ему альбомов. Один из принципов разделения, использованный автором, - функциональный. На его основе он выделил «старые» альбомы, предназначенные для хранения памятных записей от родных и близких друзей, и «новые»для демонстрации на публике. Кроме этого, автор создал еще несколько классификаций: по половозрастному (демографическому) признаку (альбомы девиц, молодых людей, женщин и мужей); по социальному («ученический», альбом «литераторов», «артистов») и по цели создания («альбом тщеславия» и «альбомы спекуляторов»). Два последних признака нуждаются в пояснении. «Альбом тщеславия», по П.Л. Яковлеву, - это книга в богато украшенном переплете, где собирались автографы и рисунки известных писателей, поэтов и художников. Рисунки для таких альбомов часто могли покупаться. Хранили подобные альбомы на отдельном столе. «Альбом спекуляторов» - это портфель с бумагами. Они не были украшены и не отличались привлекательным видом. Автографы и рисунки собирались как для собственной коллекции («на память», «по дружбе»), так и для последующей их продажи владельцам «альбомов тщеславия» [3, с. 123-124]. Можно отметить, что «спекулятор» у П.Л. Яковлева рассматривается как «торговец автографами».

Статьи П.Л. Яковлева послужили основой для последующего развития исследования альбомов. Особую ценность представляет разработанная им типология, так как она является результатом непосредственного исследования социального феномена альбомов. П.Л. Яковлев попытался описать свои наблюдения над основными группами альбомов и создать типологию, приближенную к научной.

Новое направление в изучении альбомов связано с публикациями текстов из них. Они издавались в исторических журналах («Русский архив», «Русская старина», «Исторический вестник», «Русский библиофил» и др.) и академических сборниках. Если предыдущий период рассматривал альбомы как факты повседневности, то с конца XIX в. они интересуют научное сообщество уже как историко-культурный источник. Преимущество в изучении отдавалось «старым» альбомам первой половины XIX в., а не современным.

Первые археографические описания альбомов в отечественной науке и анализ их текстов появились одновременно с созданием в системе академических учреждений Пушкинского Дома. Большая заслуга в этом деле принадлежит Б.Л. Модзалевскому. Речь идет о таких работах, как «Из альбомной старины» [16], «Альбомчики А.М. Вындомского и П.А. Осиповой» [17], «Альбом А.Е. Шиповой, рожд. графини Комаровской» [18] и др., опубликованных в сборнике «Пушкин и его современники», выходившем в 1903-1930-х гг. [19]. Альбомы стали одним из важных источников для проведения текстологических исследований и атрибуции текстов. Все публикации Б.Л. Модзалевского в сборнике «Пушкин и его современники» строятся по следующей схеме: краткое описание внешнего вида альбома и рисунков, находящихся в нем; информация о наиболее известных автографах и воспроизведение альбомного текста в авторской орфографии с указанием помет и исправлений. Текст снабжен комментариями, примечаниями и научным аппаратом. Кроме работ Б.Л. Модзалевского, описания альбомов встречаются на страницах исторических периодических изданий, например, в статье 
Н. Барсукова «Альбом автографов Н.Д. Иванчина-Писарева» [20].

Интерес Б.Л. Модзалевского к собиранию рукописей А.С. Пушкина и его окружения способствовал смещению акцентов в истории изучения русского альбома с социологии на литературоведение. Традиция рассматривать альбомы как собрание текстов и источник для восстановления литературных связей сохранится в работах представителей Пушкинского Дома в дальнейшем.

Развитие исследований альбомов во второй половине XX в. связано, в первую очередь, с деятельностью М.П. Алексеева, который возглавлял Сектор пушкиноведения (1955-1957), и Сектор взаимосвязей русской и зарубежной литератур (1956-1981) ИРЛИ АН СССР [21]. Во время подготовки к изданию писем иностранных писателей ученый столкнулся с феноменом собирательства и коллекционирования автографов и составления альбомов в европейской культуре. Для нас важной является его вступительная статья «Из истории русских рукописных собраний» в книге «Неизданные письма иностранных писателей XVIII-XIX веков из ленинградских рукописных собраний» [4]. Альбомы, согласно М.П. Алексееву, должны рассматриваться в контексте собирания рукописей (XVIII-XIX вв.). Автор прослеживает интерес к коллекционированию автографов на примере русских альбомов XIX в., не ставя своей целью рассмотреть эволюцию альбомной культуры. Он выделяет ее наиболее важные этапы: эпоха «домашних» альбомов (до 1820-х гг.), «переломный» этап и расцвет альбомной культуры (1820-1840-е гг.), период «упадка» (с 1850-1860-х гг. до конца XIX в.).

Работа М.П. Алексеева внесла важный вклад в типологизацию альбомов. Отталкиваясь от типологии П.Л. Яковлева, он разработал собственные подходы к классификации. Не ставя задачи создания полноценной системы, М.П. Алексеев предложил возможные варианты группировки альбомов. Вся типология, предложенная исследователем, относилась к рукописям 1800-1850-х гг., для материалов второй половины XIX в. она не разрабатывалась. Ученый лишь отмечает, что альбомы «продолжали свою жизнь, - правда более глухую, менее публичную, чем прежде» $[4$, с. $116]$ и не имели прежнего влияния в обществе. При этом он замечает, что «автографические коллекции, создававшиеся в России во второй половине XIX в., изучены еще очень мало, а судьба многих из них представляется еще недостаточно ясной» [4, с. 118]. В основу предложенной типологии легли два признака: гендерный («мужские» и «женские» альбомы) [4, с. 10] и функциональный («профессиональные» альбомы, «семейные» - личные, домашние, «светские» - парадные или салонные). Соответственно, «профессиональные» альбомы относились к литературно-художественным сообществам, «семейные» - это «заветные альбомы, с их интимными записями для дружеских сердец», «светские» - ориентированные на публику, напоминающие «летопись семейных литературных знакомств» [4, с. 9].

Продолжением исследований М.П. Алексеева стала работа В.Э. Вацуро «Литературные альбомы в собрании Пушкинского Дома (1750-1840-е годы)», посвященная обзору альбомных материалов из Рукописного отдела ИРЛИ АН СССР [5]. Ученый рассматривал развитие альбомной культуры XVIII-XIX вв. с точки зрения истории литературы и литературного быта. Такая установка на историко-литературное исследование проявлялась в отношении анализа формы и содержания альбомных текстов.

Вслед за М.П. Алексеевым В.Э. Вацуро разделяет альбомы на «светские» и «профессиональные» («альбом литераторов»). Общая типология, созданная исследователем, не стремится к строгости. Она тесно связана с его периодизацией альбомной культуры, в которой ранние альбомы XVIII в. лишь упоминаются, а подробное рассмотрение начинается с XIX в., для которого В.Э. Вацуро выделил два основных периода: время увлечения альбомами (1800-1810-е гг.); расцвет альбомной культуры (1820-1840-е гг.). Альбомы этих периодов делятся на альбомы «литературного быта» и «массовые» альбомы, которые не относятся к литературной среде [5, с. 40]. При этом в категорию «массовых» [5, с. 49] вошли две подгруппы: «альбомы учебных заведений» (пансионские, гимназические, лицейские, студенческие), и «провинциальные», которые представляли собой подражания альбомам «литературного быта» [5, с. 44].

Для периода 1800-1810-х гг. среди альбомов «литературного быта» В.Э. Вацуро выделяет две подгруппы: «литературные» и «литераторские» $[5$, с. 10-11]. Различаются они тем, что первая подгруппа представлена рукописными альбомами, владельцы которых не являлись писателями или поэтами, но были связаны с литературной средой; альбомы второй подгруппы 
содержали записи профессиональных литераторов. Во втором периоде (1820-1840-е г.) типология меняется, альбомы «литературного быта» подразделяются на «литературно-домашние», «светские/парадные» [5, с. 12-27], «профессиональные» и альбомы «культурных гнезд» [5, с. 49]. Последняя подгруппа - это альбомы, которые вели родственники или знакомые писателей и поэтов, проживающие в провинции.

Кроме того, вне зависимости от периодов В.Э. Вацуро указывает на существование двух функциональных типов: «альбомы-коллекции» и «альбомы-сборники». Первые содержали в себе автографы знаменитых людей, вторые «каллиграфические писарские копии популярных стихов» [5, с. 33]. Как и у М.П. Алексеева, типология альбомов у В.Э. Вацуро не была завершена и остановилась на периоде $1840-1850$-х годов. Он планировал в дальнейшем написать обзорное исследование, посвященное альбомам второй половины XIX в., но данной работе не суждено было осуществиться. Интересно, что ученый верил в еще один период «оживления» альбомной культуры в будущем [5, с. 56].

Важнейшей спецификой работы В.Э. Вацуро является сосредоточенность на материале одного собрания (ИРЛИ АН СССР), которая не позволяла рассмотреть альбомную культуру в целом. Типология строилась на приоритете литературной ценности альбомов, происходивших из литературной среды. Альбомы литераторов и их окружения рассматривались как более ценные, остальные включались в группу «массовые» альбомы. При этом полностью не учитывалась такая разновидность, как «полковые» альбомы. Не совсем ясна разница и в разделении на «парадный», «светский», «салонный» альбомы. Часто под этими названиями имелся в виду один и тот же тип. Называя группу альбомов «салонными», исследователь пишет: «Будучи порождением салонной культуры, альбом не всегда являлся порождением салона» [5, с. 32].

То, что В.Э. Вацуро не удалось сформировать универсальную типологию, хорошо видно на примере «альбомов-сборников», о которых говорится, что их легко перепутать с «рукописными сборниками текстов». Единственным отличием первых являются редкие автографические записи деятелей культуры [5, с. 33]. Не просматриваются и четкие параметры разграничения альбомов и визитных книг ${ }^{4}$, по поводу которых исследователь писал, что «альбом грозился превратиться в памятную книгу почетных посетителей» [5, с. 32], но различия этих двух видов памятников никак не характеризуются.

Несмотря на незавершенность, работа В.Э. Вацуро, безусловно, стала важным вкладом в историю изучения русских альбомов, многие ее положения еще должны найти свое дальнейшее развитие.

Семиотический подход к исследованию альбомов попыталась применить представитель московско-тартуской школы Л.И. Петина (ученица М.Ю. Лотмана). С ее исследованием «Художественная природа литературного альбома первой половины XIX века» [6] связана группа статей, посвященных альбомной культуре: «Структурные особенности альбома пушкинской эпохи» [22] и «Об особенностях альбомной литературы» [23]. В своих работах Л.И. Петина рассматривает альбом как важное средство коммуникации XIX века. Большое место в концепции занимают рассуждения о «диалогичности» альбома и его игровой природе. Автор также пыталась рассмотреть построение альбомных текстов с точки зрения принципов организации устной речи [24]. Проблемы типологии в задачи исследования не входили, поэтому Л.И. Петина воспользовалась существующей на тот момент классификацией М.П. Алексеева и В.Э. Вацуро: «альбом-сборник», «альбом-коллекция», «литературнобытовой» альбом. Многие ее выводы спорны, а утверждения, к сожалению, не подкреплены достаточными доказательствами. Стремление рассмотреть альбом как средство коммуникации, построенное на принципах устной речи и имеющее игровую природу, сегодня воспринимается как попытка искусственной «подгонки» понимания русской альбомной культуры под положения семиотической школы [25; 26].

Литературовед Б.Ф. Егоров, также во многом разделявший взгляды московско-тартуской школы, в статье «Альбом как модель эстетических вкусов владельца» [27] рассматривает «персональный» альбом в качестве источника для изучения культурологии и «истории и теории литературной критики» [27, с. 45]. В развитии альбомов исследователь выделяет три этапа: «дворянский» (до 1850-1860-х гг.), «разночинный альбом шестидесятников» (бытующий в среде духовенства, мещан, разночинцев) и «советский послевоенный» (сборник песен и частушек) 1950-1970-х гг. [27, c. 47-48]. Б.Ф. Егоровым была предпринята попытка формирования собственной типологии для альбомов второй половины XX в.: по 
авторству пишущих («многоавторские» и «персональные») и по социально-половой принадлежности («мужские» и «женские», «альбомы школьниц», «тюремные») [27, с. 46-47].

С конца 1980-х гг. альбомам был посвящен ряд исследований, в которых основное внимание уделялось разработке типологии и функций альбома XX в. (анкета, песенник и т. д.). В результате альбом постепенно стал рассматриваться в качестве важного источника в литературоведческих и фольклористических исследованиях. Здесь следует отметить работы: А.Ю. Ханютин «Школьный рукописный альбом-песенник: новый успех старого жанра» [7], М.В. Калашникова «Современный альбом: типология, поэтика и функции» [8], А.В. Чеканова «Рукописный девичий альбом: традиция, стилистика, жанровый состав» [9].

«Альбом-коллекция» исследовался Е.Д. Конусовой в диссертации «Коллекция автобиографий и библиографических материалов С.А. Венгерова: формирование и историко-литературное значение» [28] и в статье «"Я видел альбомы, которые драгоценнее всех диссертаций...”: домашний альбом Павла Константиновича Симони» [29]. Однако сами эти работы не посвящены изучению альбомов непосредственно, автор сосредоточила внимание на культуре «автобиографии» (автобиографических сборников конца XIX-XX вв.) с альбомом в качестве одного из источников.

Самарский историк М.М. Леонов в статьях «Альбомные коллекции как исторический источник (по материалам ГЦТМ им. А.А. Бахрушина)» [30] и «Театральные альбомы в России рубежа XIX - XX вв.» [31] предпринял попытку подойти к альбому как источнику по истории пореформенного общества в России и проследить эволюцию развития альбомов второй половины XIX века. В диссертационном исследовании «Патронат и протежирование: российские салоны второй половины XIX - начала XX вв.» он предлагает использовать альбом как инструмент для реконструкции биографий русской элиты второй половины XIX века [10].

Рассмотрение отечественной историографии, посвященной изучению альбомов, позволяет сделать общие выводы.

Прежде всего, следует отметить, что рукописный альбом изучался неравномерно. Если не считать работы искусствоведов, в науке господствовал историко-филологический взгляд, рассматривавший альбом как текст. Исходя из этого, на протяжении долгого времени иссле-

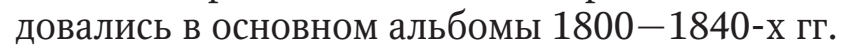

(эпохи их «расцвета»), тогда как альбомы других хронологических периодов изучались значительно реже. При этом неоднократно предпринимались попытки рассмотреть эволюцию этого явления, но ее универсальный вариант до сих пор так и не сформирован. В настоящий момент фокус в изучении перемещается на современные «анкеты», «песенники», «блокноты» XX века.

Сегодня наиболее актуальной задачей изучения русских альбомов по-прежнему остается формирование единой целостной типологической системы, которая могла бы лечь в основу исследования этого явления и обеспечить описание и систематизацию рукописных альбомов.

\section{Примечания}

1 О Н. Виршеевском известно только то, что он называл себя «ученым из Колтовской». По всей вероятности, он относился к среде мелкого или среднего чиновничества и проживал в районе Колтовской слободы Санкт-Петербурга.

2 Журнал «Благонамеренный» издавался в СанктПетербурге в 1818-1826 годах.

3 Спор о русском литературном языке возник в 1803 г., после выхода статьи А.С. Шишкова «Рассуждения о старом и новом слоге российского языка» [14]. Статья была направлена против реформы языка, задуманной Н.М. Карамзиным, который пытался, с одной стороны, преодолеть разрыв между книжным и разговорным языком, с другой - сблизить понятия русского языка с западноевропейскими.

4 Визитная книга или книга посетителей - тетрадь, в которую записывались имена всех посетителей дома или учреждения, обычно находилась на столике при входе.

\section{Список источников}

1. Я Яковлев П.Л. О альбомах (из альбома К.И.И.) // Благонамеренный. 1820. Ч. 11. № XVIII. С. 373378.

2. Виршеевский Н. О альбомах (Письмо к издателю от одного ученого из Колтовской) // Благонамеренный. 1820. Ч. 10. № VII. С. 22-32.

3. Яковлев П.Л. Альбомы // Записки москвича. Москва : Тип. С. Селивановского, 1828. Т. 1. C. $122-127$.

4. Алексеев М.П. Из истории русских рукописных собраний // Неизданные письма иностранных писателей XVIII-XIX веков из ленинградских 
рукописных собраний. Москва ; Ленинград : Издво АН СССР, 1960. С. 7-122.

5. Ващуро В.Э. Литературные альбомы в собрании Пушкинского Дома (1750-1840-е годы) // Ежегодник Рукописного отдела Пушкинского Дома на 1977 год. Ленинград : Наука, 1979. С. 3-56.

6. Петина Л.И. Художественная природа литературного альбома первой половины XIX века : автореф. дис. ... канд. филол. наук. Тарту, 1988. $15 \mathrm{c}$.

7. Ханютин А.Ю. Школьный рукописный альбомпесенник: новый успех старого жанра // Массовый успех. Москва : Тип. Мин-ва культуры СССР, 1989. С. $193-209$.

8. Калашникова М.В. Современный альбом: типология, поэтика и функции : дис. ... канд. филол. наук. Тверь, 2004. 265 с.

9. Чеканова А.В. Рукописный девичий альбом: Традиция, стилистика, жанровый состав : дис. ... канд. филол. наук. Москва, 2006. 192 с.

10. Леонов М.М. Патронат и протежирование : российские салоны второй половины XIX - начала XX вв. : дис. ... докт. ист. наук. Самара, 2011. $453 \mathrm{c}$.

11. Цявловская Т.Г. Рисунки Пушкина. Москва : Искусство, 1986. 445 с.

12. Корнилова А.В. Мир альбомного рисунка: русская альбомная графика конца XVIII - первой половины XIX века. Ленинград : Искусство, 1990. $287 \mathrm{c}$.

13. Чернова В.А. Рисунки А.С. Пушкина в контексте альбомной графической культуры первой половины XIX века [Электронный ресурс] // Вестник Самарского государственного университета. 2000. № 3. Литературоведение. URL: http://vestniksamgu.ssau.ru/gum/2000web3/ litr/200030602.html (дата обращения: 18.12.2019).

14. Шишков А.С. Рассуждения о старом и новом слоге российского языка. 3-е изд. Москва : Ленанд, 2015. 368 c.

15. Купреянова Е.Н. Основные направления и течения русской литературно-общественной мысли первой четверти XIX в. // История русской литературы : в 4 т. / АН СССР. Ин-т рус. лит. (Пушкинский Дом). Ленинград : Наука, 1981. Т. 2. С. 11-35.

16. Модзалевский Б.Л. Из альбомной старины // Русский библиофил. 1916. № 6. С. 66-83.

17. Модзалевский Б.Л. Альбомчики А.М. Вындомского и П.А. Осиповой // Пушкин и его современники : материалы и исследования. Санкт-Петербург : Тип. Имп. акад. наук, 1903. Вып. I. С. 154-158.

18. Модзалевский Б.Л. Альбом А.Е. Шиповой, рожд. графини Комаровской // Пушкин и его современ- ники: материалы и исследования. Санкт-Петербург : Тип. Имп. акад. наук, 1909. Вып. ХІ. С. 79-94.

19. Пушкин и его современники : материалы и исследования. Санкт-Петербург ; Петроград ; Ленинград : Тип. Имп. акад. наук ; Тип. Рос. акад. наук ; Изд-во АН СССР, 1903-1930. Вып. 1-39.

20. Барсуков Н. Альбом автографов Н.Д. ИванчинаПисарева // Старина и новизна. 1905. Кн. Х. C. $470-540$.

21. Левин Ю.Д. Михаил Павлович Алексеев // Материалы к биобиблиографии ученых СССР. Сер. литературы и языка. Москва : Изд-во АН СССР, 1972. Вып. 9. С. 10-29.

22. Петина Л.И. Структурные особенности альбома пушкинской эпохи // Проблемы типологии русской литературы : Труды по русской и славянской филологии. Литературоведение. Ученые записки Тартуского университета. Тарту, 1985. Вып. 645. C. $21-36$.

23. Петина Л.И. Об особенностях альбомной литературы // Пушкинские чтения : сб. статей. Таллинн : Ээсти раамат, 1990. С. 108-128.

24. Гаспаров Б.М. Устная речь как семиотический объект // Ученые записки Тартуского университета. Тарту, 1978. Вып. 442. С. 63-112.

25. Бахтин М.М. Творчество Франсуа Рабле и народная культура средневековья и Ренессанса. Москва : Худож. лит., 1965.451 с.

26. Бахтин М.М. Проблемы поэтики Достоевского. Москва : Сов. писатель, 1963.363 с.

27. Егоров Б.Ф. Альбом как модель эстетических вкусов владельца // Культура и текст. 1997. № 1. C. $45-49$.

28. Конусова Е.Д. Коллекция автобиографий и биобиблиографических материалов С.А. Венгерова: формирование и историко-литературное значение : дис. ... канд. филол. наук. Санкт-Петербург, 2016. 242 c.

29. Конусова Е.Д. «Я видел альбомы, которые драгоценнее всех диссертаций...»: домашний альбом Павла Константиновича Симони // Пятые Лихачевские чтения. Русская культура: история и экология : материалы междунар. науч. конф. (28 сентября -1 октября 2016 г.). Ясная Поляна, 2016. C. 93-99.

30. Леонов М.М. Альбомные коллекции как исторический источник (по материалам ГЦТМ им. А.А. Бахрушина) // Вестник Самарского государственного университета. 2009. № 7 (73). C. $63-68$.

31. Леонов М.М. Театральные альбомы в России рубежа XIX-XX вв. // Вестник Самарского муниципального института управления. 2009. № 10. C. $120-125$. 


\title{
Study of Handwritten Albums in the National Science in the 19th - Early 21st Century
}

\author{
Aleksandra V. Petrova, \\ National Library of Russia, 18 Sadovaya Str., St. Petersburg, 191069, Russia \\ Institute of History of St. Petersburg State University, 5 Mendeleyevskaya Line, St. Petersburg, 199034, Russia \\ ORCID 0000-0002-6736-5309; SPIN 1275-6779 \\ E-mail: aleksandra-petr@mail.ru
}

\begin{abstract}
The article considers bibliography of study of Russian albums of the 19th - early 21th century. Development of Russian historiography of this topic was uneven. The author consistently describes three main stages in the study of handwritten album: response of contemporaries and public discussions of this phenomenon; the beginning of publication of album texts; introduction of albums to science. The article presents the main directions of academic research. The author considers domestic publications about Russian albums, starting from the first quarter of the 19th century through the beginning of the 21st century. The analysis of the literature on albums was carried out from the point of view of the author's area of interests (study of the history of autograph albums, their typology and functions), the nature and scope of the objects studied, the main tasks of these works and their methodological principles. The main problem in historiography is development of typology of handwritten albums. The choice of typology as the main subject of analysis is explained by the fact that in general this phenomenon of Russian culture of the late 18 th - first quarter of the 20th century was not studied systematically. The author notes that in order to create the full picture of Russian album culture, it is necessary, first of all, to build the typological system. The result of the author's research is the complete review of publications on Russian handwritten albums published from 1820 to 2016. The author highlights the main typological principles of albums that are typical for different approaches, research schools and directions of study. The article notes that many issues have not been considered until the present moment. The approach to album as a source of history of individual writing and sociocultural behaviour is beyond the study, while the comprehensive analysis of Russian album, writing and signature in it is one of the promising directions of research of the culture of everyday life of the 18th -20 th centuries. The general conclusion of the article focuses on the absence of universal typology in historiography, which the author suggests to present in the following works.
\end{abstract}

Key words: art criticism, art culture, everyday culture, autographs, album culture, visiting books, collecting, handwritten albums, Institute of Russian Literature (Pushkin House) of the Russian Academy of Sciences, typology of handwritten albums, individual writing, bibliography, historiography.

Citation: Petrova A.V. Study of Handwritten Albums in the National Science in the 19th - Early 21st Century, Bibliotekovedenie [Russian Journal of Library Science], 2020, vol. 69, no. 3, pp. 271-280. DOI: 10.25281/0869-608X-2020-69-3-271-280.

\section{References}

1. Yakovlev P.L. About the Albums: (From the K.I.I. Album), Blagonamerennyi [Well-Meaning], 1820, part 11, no. XVIII, pp. 373-378 (in Russ.).

2. Virsheevsky N. About the Albums (A Letter to the Publisher from a Scientist from Koltovskaya), Blagonamerennyi [Well-Meaning], 1820, part 10, no. VII, pp. 22-32 (in Russ.).
3. Yakovlev P.L. Albums, Zapiski moskvicha [A Muscovite's Notes]. Moscow, S. Selivanovskogo Publ., 1828, vol. 1, pp. 122-127 (in Russ.).

4. Alekseev M.P. From the History of Russian Manuscript Collections, Neizdannye pis'ma inostrannykh pisatelei XVIII-XIX vekov iz leningradskikh rukopisnykh sobranii [Unpublished Letters of Foreign 
Writers of the 18th -19 th Centuries from Leningrad Manuscript Collections]. Moscow, Leningrad, AN SSSR Publ., 1960, pp. 7-122 (in Russ.).

5. Vatsuro V.E. Literary Albums in the Pushkin House (1750s-1840s), Ezhegodnik Rukopisnogo otdela Pushkinskogo Doma na 1977 god [Yearbook of the Manuscript Department of the Pushkin House for 1977]. Leningrad, Nauka Publ., 1979, pp. 3-56 (in Russ.).

6. Petina L.I. Khudozhestvennaya priroda literaturnogo al'boma pervoi poloviny XIX veka [The Artistic Nature of the Literary Album of the First Half of the 19th Century], cand. philol. sci. diss. abstr. Tartu, 1988, $15 \mathrm{p}$.

7. Khanyutin A.Yu. School Handwritten Songbook Album: A New Success of the Old Genre, Massovyi uspekh [Mass Success]. Moscow, Ministerstva Kul'tury SSSR Publ., 1989, pp. 193-209 (in Russ.).

8. Kalashnikova M.V. Sovremennyi al'bom:tipologiya, poetika ifunktsii [Modern Album: Typology, Poetics and Functions], cand. philol. sci. diss. Tver, 2004, 265 p.

9. Chekanova A.V. Rukopisnyi devichii al'bom: Traditsiya, stilistika, zhanrovyi sostav [Handwritten Girl's Album: Tradition, Style, Genre Composition], cand. philol. sci. diss. Moscow, 2006, 192 p.

10. Leonov M.M. Patronat i protezhirovanie: rossiiskie salony vtoroi poloviny XIX - nachala XX vv. [Patronage and Favoritism: Russian Saloons of the Second Half of the 19th - Early 20th Centuries], doct. hist. sci. diss. Samara, 2011, 453 p.

11. Tsyavlovskaya T.G. Risunki Pushkina [Pushkin's Drawings]. Moscow, Iskusstvo Publ., 1986, 445 p.

12. Kornilova A.V. Mir al'bomnogo risunka: russkaya al'bomnaya grafika kontsa XVIII - pervoi poloviny XIX veka [The World of Album Drawing: Russian Album Graphics of the Late 18th - First Half of the 19th Century]. Leningrad, Iskusstvo Publ., 1990, $287 \mathrm{p}$.

13. Chernova V.A. A.S. Pushkin's Drawings in the Context of Album Graphic Culture of the First Half of the 19th Century, Vestnik Samarskogo gosudarstvennogo universiteta [Bulletin of the Samara State University], 2000, no. 3: Literaturovedenie [Literary Studies]. Available at: http://vestniksamgu.ssau.ru/ gum/2000web3/litr/200030602.html (accessed 18.12.2019) (in Russ.).

14. Shishkov A.S. Rassuzhdeniya o starom i novom sloge rossiiskogo yazyka [Discussions about the Old and New Style of the Russian Language]. Moscow, Lenand Publ., 2015, 368 p.

15. Kupreyanova E.N. The Main Directions and Trends of the Russian Literary and Social Thought in the First Quarter of the 19th Century, Istoriya russkoi literatury: $v 4 t$. [History of Russian Literature: in 4 volumes]. Leningrad, Nauka Publ., 1981, vol. 2, pp. 11-35 (in Russ.).

16. Modzalevsky B.L. From the Album Antiquity, Russkii bibliofil [Russian Bibliophile], 1916, no. 6, pp. 66-83 (in Russ.).

17. Modzalevsky B.L. Little Albums by A.M. Vyndomsky and P.A. Osipova, Pushkin i ego sovremenniki: materialy $i$ issledovaniya [Pushkin and His Contemporaries: Materials and Researches]. St. Petersburg, Imperatorskoi Akademii Nauk Publ., 1903, issue I, pp. 154-158 (in Russ.).

18. Modzalevsky B.L. Album by A.E. Shipova, born Countess Komarovskaya, Pushkin i ego sovremenniki: Materialy $i$ issledovaniya [Pushkin and His Contemporaries: Materials and Researches]. St. Petersburg, Imperatorskoi Akademii Nauk Publ., 1909, issue XI, pp. 79-94 (in Russ.).

19. Pushkin i ego sovremenniki: materialy $i$ issledovaniya [Pushkin and His Contemporaries: Materials and Researches]. St. Petersburg, Petrograd, Leningrad, Imperatorskoi Akademii Nauk Publ., Rossiiskoi Akademii Nauk Publ., AN SSSR Publ., 1903-1930, issue $1-39$.

20. Barsukov N. Album of Autographs by N.D. IvanchinPisarev, Starina i novizna [Antiquity and Novelty], 1905, book X, pp. 470-540 (in Russ.).

21. Levin Yu.D. Mikhail Pavlovich Alekseev, Materialyk biobibliografii uchenykh SSSR. Ser. literatury i yazyka [Materials for Biobibliography of the USSR Scientists. Literature and Language Series]. Moscow, AN SSSR Publ., 1972, issue 9, pp. 10-29 (in Russ.).

22. Petina L.I. Structural Features of the Pushkin Era Album, Problemy tipologii russkoi literatury: Trudy po russkoi i slavyanskoifilologii. Literaturovedenie. Uchenye zapiski Tartuskogo universiteta [Issues of Russian Literature Typology: Works on Russian and Slavic Philology. Literary Studies. Scientific Notes of the University of Tartu]. Tartu, 1985, issue 645, pp. 21-36 (in Russ.).

23. Petina L.I. On the Features of Album Literature, Pushkinskie chteniya: Sb. Statei [Pushkin Readings: collected articles]. Tallinn, Eesti Raamat Publ., 1990, pp. 108-128 (in Russ.).

24. Gasparov B.M. Oral Speech as a Semiotic Object, Uchenye zapiski Tartuskogo universiteta [Scientific Notes of the University of Tartu]. Tartu, 1978, issue 442, pp. 63-112 (in Russ.).

25. Bakhtin M.M. Tvorchestvo Fransua Rable i narodnaya kul'tura srednevekov'ya i Renessansa [Works of Francois Rabelais and the Folk Culture of the Middle Ages and Renaissance]. Moscow, Khudozhestvennaya Literatura Publ., 1965, 451 p.

26. Bakhtin M.M. Problemy poetiki Dostoevskogo [Issues of Dostoevsky's Poetics]. Moscow, Sovietskii Pisatel' Publ., 1963, 363 p. 
27. Egorov B.F. Album as a Model of the Owner's Aesthetic Tastes, Kul'tura itekst [Culture and Text], 1997, no. 1, pp. 45-49 (in Russ.).

28. Konusova E.D. Kollektsiya avtobiografii i biobibliograficheskikh materialov S.A. Vengerova: formirovanie $i$ istoriko-literaturnoe znachenie [S.A. Vengerov's Collection of Autobiographies and Biobibliographic Materials: Its Formation and Historical and Literary Significance], cand. philol. sci. diss. St. Petersburg, 2016, 242 p.

29. Konusova E.D. "I Have Seen Albums That Are More Precious Than All Dissertations...”: Pavel Konstantinovich Simoni's Home Album, Pyatye Likhachevskie chteniya. Russkaya kul'tura: istoriya i ekologiya: materialy mezhdunar. nauch. konf. (28 sentyabrya-
1 oktyabrya 2016 g.) [The Fifth Likhachov Readings. Russian Culture: History and Ecology: Proceedings of the Int. Sci. Conf. (September 28 - October 1, 2016)]. Yasnaya Polyana Publ., 2016, pp. 93-99 (in Russ.).

30. Leonov M.M. Album Collections as a Historical Source (Based on the Materials of the A.A. Bakhrushin State Central Theatre Museum), Vestnik Samarskogo gosudarstvennogo universiteta [Bulletin of the Samara State University], 2009, no. 7 (73), pp. 63-68 (in Russ.).

31. Leonov M.M. Theatre Albums in Russia at the Turn of the 19th-20th Centuries, Vestnik Samarskogo munitsipal'nogo instituta upravleniya [Bulletin of the Samara Municipal Institute of Management], 2009, no. 10, pp. 120-125 (in Russ.).

\section{Анонс}

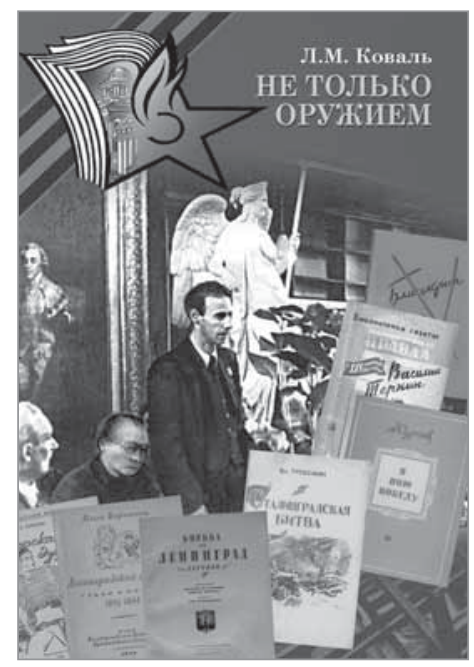

Коваль Л.М. Не только оружием: Российская государственная библиотека в годы Великой Отечественной войны. Москва : Пашков дом, 2020. 206, [1] с. : ил.

Книга рассказывает о людях, которые во время Великой Отечественной войны сберегли национальное достояние - фонд Российской государственной библиотеки, спасли ее здания, оперативно и качественно выполняли информационные нужды фронта и тыла.

В сборнике использованы статьи автора, опубликованные в разные годы в газетах, научных изданиях и не потерявшие свою актуальность. Публикации дополнены источниками из архива Российской государственной библиотеки, документами и неопубликованными прежде материалами, хранящимися в фонде Музея истории Библиотеки.

Воспоминания детей, переживших войну, во взрослом возрасте ставших сотрудниками Библиотеки и ее ветеранами, также представлены в данном сборнике. Книга иллюстрирована, является эксклюзивным изданием.

Справки и заказ изданий:

119019, Москва, ул. Воздвиженка, д. 3/5

Российская государственная библиотека, Издательство «Пашков дом», отдел книжных изданий Pashkov_Dom@rsl.ru,Pashkov_Dom.Book@rsl.ru http://store.rsl.ru/service/pashkov_dom +7 (495) 695-37-31 